\title{
PEMBARUAN VISUAL LOGO HTII SEBAGAI UPAYA REBRANDING ORGANISASI PROFESI NON PROFIT
}

\author{
Amalia Setyowulan$^{1}$, Endah Setyaningsih ${ }^{2}$, dan Asrullah Ahmad ${ }^{3}$ \\ ${ }^{1}$ Program Studi Desain Komunikasi Visual, Universitas Tarumanagara \\ Surel: amaliasetyowulan@gmail.com \\ ${ }^{2}$ Program Studi Teknik Elektro, Universitas Tarumanagara \\ Surel:endahs@ft.untar.ac.id \\ ${ }^{3}$ Program Studi Desain Komunikasi Visual, Universitas Bunda Mulia \\ Surel: asrullahmanyala@gmail.com
}

\begin{abstract}
Professional organization is a forum for the scientific community in a branch or across science and technology, or a field of professional activity guaranteed by the state to develop professionalism and professional ethics in society [1]. Some of the well-known professional organizations include the Indonesian Doctors Association (IDI), the Indonesian Teachers Association (PGRI), the Indonesian Architects Association (IAI). There are also specific professional organizations, including the Indonesian Interior Design Association (HDII), the Association of Indonesian Landscape Architects (IALI), and the Indonesian Illuminating Engineering Society (HTII). HTII was founded on 7 May 1991 in Jakarta, and is the only forum in the lighting sector in Indonesia. Currently HTII members are more specific, namely the professional circles of illuminating engineering. This is evidenced by the HTII social media which only has 213 followers, for some people this figure does sound a lot, but for an organization that was founded in 1991 this figure is felt to be very small. This can then become the basis for HTII to make efforts to introduce the name, image of the organization and vision mission that has been carried for a long time, in order to expand the network both from professionals, prospective young professionals and nonprofessionals who are interested in knowledge lighting. Rebranding is necessary because HTII already has a logo and visual identity but does not have other supporting media. On the other hand, the logo from HTII is also considered to lack good clarity in legibility in a certain size scale. For this reason, in this PKM, one of the rebranding efforts is to create a new logo design for HTII. Currently, 5 new logo designs have been produced, which are ready to be defined.
\end{abstract}

Keywords: Logo, Visual, rebranding, HTII, professional organizations

\begin{abstract}
ABSTRAK
Organisasi profesi, merupakan wadah bagi masyarakat ilmiah dalam suatu cabang atau lintas ilmu pengetahuan dan teknologi, atau suatu bidang kegiatan profesi yang dijamin oleh negara untuk mengembangkan profesionalisme dan etika profesi dalam masyarakat [1]. Beberapa organisasi profesi yang sudah banyak dikenal antara lain Ikatan Dokter Indonesia (IDI), Persatuan Guru Republik Indonesia (PGRI), Ikatan Arsitek Indonesia (IAI). Terdapat juga organisasi profesi yang spesifik, antara lain Himpunan Desain Interior Indonesia (HDII), Ikatatan Arsitek Lanskap Indonesia (IALI), dan Himpunan Teknik Iluminasi Indonesia (HTII). HTII didirikan pada 7 Mei 1991 di Jakarta, dan merupakan satu-satunya wadah di bidang pencahayaan di Indonesia. Saat ini anggota HTII lebih ke kalangan spesifik saja yaitu kalangan profesional teknik iluminasi. Hal ini dibuktikan dengan media sosial HTII yang hanya memiliki 213 followers, bagi sebagaian orang angka ini memang terdengar banyak, namun bagi organisasi yang berdiri dari tahun 1991 angka ini dirasa sangat sedikit. Hal ini kemudian bisa untuk menjadi dasar bagi HTII untuk melakukan upaya dalam mengenalkan nama, citra organisasi dan visi-misi mulia yang diusung sejak lama, agar bisa memperluas jaringan baik dari kalangan profesional, professional muda dan non profesional yang tertarik akan ilmu pencahayaan. Rebranding diperlukan karena HTII sudah mempunyai logo dan identitas visual namun belum memiliki media-media pendukung lain. Di sisi lain logo dari HTII juga dianggap kurang memiliki clarity yang baik secara keterbacaan dalam skala ukuran tertentu. Untuk itu dalam PKM ini, salah satu upaya rebranding adalah dengan membuat desain logo baru untuk HTII. Saat ini telah dihasilkan 5 desain logo baru, yang siap untuk ditetapkan.
\end{abstract}

Kata Kunci: Logo, Visual, rebranding, HTII, organisasi profesi.

\section{PENDAHULUAN}

Pembangungan infrastruktur kian gencar dilaksanakan di Indonesia seiring dengan semakin banyaknya kebutuhan disektor industri yang diharapkan mampu membantu mempercepat laju perkembangan perekenomian. Sebuah pembangunan infrastruktur tentunya harus dilakukan 
dengan persiapan yang sangat matang apalagi berbicara mengenai hal pencahayan. Hal ini menjadi penting karena sebuah pembangunan bukan hanya mempertimbangkan keamanan dan keindahan serta pemenuhan kebutuhan biasa saja sebuah pembangunan haruslah memenuhi standard keamanan termasuk pencahayaan yang sejatinya sangat dibutuhkan untuk membantu penglihatan. Hal-hal seperti ini tentu harus dikerjakan oleh tenaga-tenaga yang memang sudah ahli di bidang ini, bidang yang biasanya disebut dengan bidang iluminasi.

Indonesia sendiri memiliki Himpunan Teknik Iluminasi Indonesia (HTII) yang selalu aktif dalam membantu memenuhi kebutuhan pembangunan infrastruktur dalam berbagai sektor yang membutuhkan gagasan dan pandangan secara keilmuwan tentang pencahayaan atau iluminasi. HTII sendiri telah lama berdiri yaitu pada 7 Mei 1991 oleh prakarsa Ir.TW Simbolon, MSc dan Ir, Ketut Kontra MSc, di Jakarta yang masih kokoh hingga saat ini. Selain membantu pembangunan infrastruktur secara keilmuwan dan aplikatif secara profesional, HTII juga aktif memberikan informasi terkait pencahayaan kepada masyarakat luas melalui seminar dan webinar. Hal ini tentu sesuai dengan visi misi HTII yang menginginkan terselenggaranya pembangunan dan pengelolaan sarana iluminasi oleh tenaga kerja bangsa Indonesia dan menjalin kerjasama dengan lembaga, asosiasi/organisasi, dan industri terkait, langsung ataupun tidak langsung, baik di dalam maupun luar negeri.

Harapan dan visi misi dari HTII tentunya adalah harapan yang mulia bagi terbentuknya bangsa yang professional dan mandiri. Dalam rangka mewujudkan visi yang jujur, mandiri dan profesional perlu dilakukan beberapa penekanan identitas dalam setiap kegiatan acara, promosi, penawaran kerja sama, dan juga hal yang bersifat internal lainnya yang ada dalam agenda HTII. Tujuannya adalah membuat informasi yang disampaikan agar jauh lebih menarik secara visual, kemudian memberikan kemungkinan agar organisasi professional seperti HTII berpotensi untuk tersebar dan diketahui lebih luas lagi oleh masyarakat. Saat ini hanya terwujud untuk kalangan spesifik saja yaitu kalangan professional teknik iluminasi. Hal ini dibuktikan dengan media sosial HTII yang hanya memiliki 213 followers, bagi sebagian orang angka ini memang terdengar banyak, namun bagi organisasi yang berdiri dari tahun 1991 angka ini dirasa sangat sedikit. Hal ini kemudian bisa untuk menjadi dasar yang menyebabkan HTII perlu melakukan upaya-upaya lain dalam menyebarkan nama dan citra organisasi dan visi-misi mulia dan bijaksana yang diusung sejak lama, agar bisa memperluas jaringan baik dari kalangan profesional, calon profesional, calon profesional muda dan non profesional yang tertarik akan ilmu pencahayaan.

Salah satu langkah konkrit yang bisa dilakukan oleh HTII adalah melakukan pembaruan logo dan corporate visual identity agar lebih bisa mencakup hal-hal dan tujuan yang telah dibahas sebelumnya yaitu penyebar luasan visi misi, pemberian informasi dan menambah jaringan anggota baru untuk organisasi HTII. Bosch, de Jong \& Elving dalam Lisfya dan Dawami menyatakan bahwa identitas visual korporat bisa memainkan peran yang signifikan dalam mempresentasikan sebuah organisasi kepada pihak-pihak yang berkaitan secara internal maupun external. Dalam penelitian yang dilakukan oleh Lisfya dan Dawami (2018) memaparkan pendapat bahwa penciptaan identitas visual bagi organisasi non profit masih sangat terbatas. Dalam penelitian ini juga disebutkan bahwa kata corporate dalam kalimat corporate visual identity yang secara harafiah berarti sebuah perusahaan, juga bisa dimaknai sebagai sebuah entitas lain seperti organisasi, komunitas dan tentunya organisasi non profit. Dengan pemaparan tersebut maka bisa disimpulkan bahwa untuk merancang identitas visual dari organisasi non profit HTII bisa dilakukan dengan cara yang sama dengan cara merancang corporate visual identity. 
Rebranding logo HTII, sekaligus akan menjadi branding organisasi profesi non profit, seperti HTII. Menurut (Yugih, dkk, 2017), branding sering diidentikkan dengan keberadaan sebuah institusi bisnis yang berorientasi profit. Namun dalam perkembangannya sudah banyak profesi non profit seperti organissai pemerintah, LSM, dan lembaga pendidikan seperti perguruan tinggi merasa perlu melakukan upaya branding. Berdasarkan ini, HTII, yang salah satu visinya selaras dengan perguruan tinggi, yaitu lebih menekankan pendidikan, maka melakukan branding sudah merupakan keharusan untuk saat ini.

\section{METODE PELAKSANAAN}

Metode pembaruan dan perancangan logo HTII mengikuti cara yang telah dilakukan oleh Listya dan Dawami (2018) yang juga merancang sebuah corporate visual identity untuk sebuah organisasi non profit. Dilandasi dengan kesamaan tersebut, cara yang dilakukan pada Listya dan Dawami pada penelitiannya dinilai mampu dan mumpuni untuk digunakan sebagai dasar perancangan pembaruan logo dan corporate visual identity dari HTII. Pelaksanaan PKM ini dilakukan antara lain melalui focus group discussion (FGD) dengan pengurus internal organisasi HTII. Guna mendapatkan informasi-informasi penting yang tidak bisa terlewatkan untuk kepentingan perancangan identitas visual nantinya dari para anggota organisasi HTII. Metode pelaksanaan lainnya berupa observasi logo yang sebelumnya telah dimiliki HTII. FGD juga dilakukan untuk menggali harapan-harapan, bentuk komunikasi apa saja yang ingin pihak HTII tonjolkan dari upaya rebranding corporate visual identity ini. Setelah mendapatkan informasi dari FGD yang dilakukan, PKM ini kemudian dilanjutkan kepada rumusan tahapan-tahapan yang menjadi rencana perancangan yang terbagi atas beberapa tahap penting yaitu:

1. Pemetaan pikiran antara tim desainer yang terdiri dari art director dan creative director dengan organisasi HTII berdasarkan informasi yang ditemukan pada proses FGD.

2. Penentuan obyek, pesan, bentuk komunikasi, nilai filosofis dan key visual yang terkait dengan HTII.

3. Perancangan alternatif logo meliputi pemetaan visual, sketsa dan proses digital

4. Melakukan diskusi internal antara tim desain dan pihak HTII untuk melakukan pemilihan logo.

5. Perancangan logo final dan pengaplikasiannya ke berbagai media yang sebelumnya telah dirancang dengan strategi creative oleh creative director (tentunya di fokuskan kepada media-media online yang sifatnya lebih luas dan cocok untuk segala rentang usia produktif)

6. Melakukan evaluasi yang berbentuk tanggapan dari masyarakat, termasuk para anggota aktif HTII melalui aplikasi google form.

7. Penyerahan master desain berupa corporate visual identity, manual book dan media-media fisik yang telah dicetak

Tentunya metode di atas juga didukung dengan metode perancangan logo berdasarkan pada prinsip desain komunikasi visual, yaitu menerapkan prinsip desain dan elemen-elemen yang dianggap wajib ada pada sebuah perancangan logo. Hardy (2011) menyatakan bahwa, logo yang sukses harus memiliki beberapa kunci yaitu memorability, simplicity, element of surprise, timeless, original, versatile, a message, scalable, execution. (Gareth Hardy,2011) dalam bukunya juga membagi kategori logo dalam beberapa jenis yaitu:

1. pictorial, yang merupakan penggambaran ilustrasi secara detail dan literal mirip seperti kondisi aslinya. 
2. simbol abstrak yaitu bentuknya tidak diketahui maknanya, makna yang muncul lebih bermakna filosifs dan merupakan bentukan dari gagasan seorang desainer contoh logo nike.

3. Emblems biasanya berbentuk illustrasi yang dikelilingi oleh bentuk dan nama dari sebuah brand contoh produk bir

4. Characters adalah bentuk logo yang menampilkan sosok mascot, seperti orang, hewan dan sosok tertentu. Seperti logo monopoli.

5. Tipografi, adalah bentuk logo yang terdiri dari huruf, atau tulisan. Bentuk ini pun terbagi lagi atas tiga hal yaitu, wordmarks yang berarti logo berbentuk tulisan kata secara utuh, seperti coca-cola. Selanjutnya ada letterforms merupakan bentuk huruf yang mewakili suatu entitas tertentu, contohnya logo Honda. Kemudian ada monograms, yaitu penggabungan dua huruf secara berhadapan, berdampingan dan lain sebagainya.

Beberapa paparan di atas dirasa cukup untuk dijadikan landasan pemikiran dalam melakukan perancangan sebuah logo untuk organisasi non profit. Selain metode perancangan tentunya logo ini juga membutuhkan metode evaluasi untuk menemukan data logo yang telah diperbarui. Uji coba terhadap logo yang sudah diperbarui sudah pernah dilakukan oleh Oei, Wibowo dan Aryanto pada tahun (2013), model yang digunakan metode test logo yang dikembangkan oleh David E. Carter. Metode David E. Carter ini mengandung beberapa point penting yaitu pembandingan logo yang akan di re-desain dengan logo yang dianggap baik sesuai dengan bidang yang sama, Konsistensi logo pada media, kemudian kontiniuitas dari logo. Beberapa variable ini kemudian yang akan menjadi penentu atau barometer keberhasilan pembaruan logo dari HTII.

Data yang ditemukan pun dianalisis dengan menggunakan metode kualitatif deskriptif, yang memahami terlebih dahulu subjek dari penelitian seperti motivasi, perilaku, tindakan dan lainnya secara holitstik dan dijelaskan dengan dengan cara deskripsi dalam bentuk kata-kata dan bahasa, Moleong (2018)

\section{HASIL DAN PEMBAHASAN}

Telah disinggung sebelumnya bahwa ini akan dilaksanakan dengan menggunakan pendekatan desain logo yang telah dilakukan Lisfya dan Dawami padah tahun 2018, serta digabungkan dengan menggunakan metode dan pendekatan desain komunikasi visual yang digagas oleh Gareth Hardy (2011). Berikut adalah penjelasan mengenai penerapan dan hasil dari perancangan ulang ini.

\section{Informasi dan brainstorming HTII}

Logo HTII, seperti pada Gambar 1, merupakan logo yang didesain bersamaan dengan berdirinya HTII. Jadi sampai saat ini, logo HTII telah digunakan selama 29 tahun. Bagi generasi yang mengikuti hadirnya HTII dari sejak berdirinya, logo ini memang masih sangat dikenal dan ada di benak member HTII, namun untuk generasi muda, nama dan logo HTII saat ini kurang dikenal. Generasi muda saat ini adalah generasi yang akrab dengan media sosial, seperti youtube dan instagram, berkaitan dengan ini, telah disinggung sebelumnya bahwa saat ini sosial media HTII terbilang memiliki followers yang masih sedikit untuk organisasi yang sudah lama eksis. Untuk itu HTII perlu melakukan banyak perubahan yang dinamis, salah satunya dimulai dengan desain ulang logo dan identitas visual yang lebih related dengan kondisi dan generasi muda saat ini.

Menurut penelitian (Ricardo dan Irwansyah, 2020), menyebutkan bahwa media sosial merupakan media digital yang digunakan banyak orang untuk melakukan komunikasi, baik individu dan kelompok, seperti pemerintah, organisasi, dan perusahaan. Melalui media sosial Instagram, 
Ahmad Zaky, CEO dan pendiri Bukalapak, menunjukkan citra yang ingin dibangun dan dilihat oleh khalayak. Menggunakan teori brand personality, Ricardo dan Irwansyah, melihat identitas yang dibangun Ahmad Zaky melalui akun instagram @ahmadzaky.

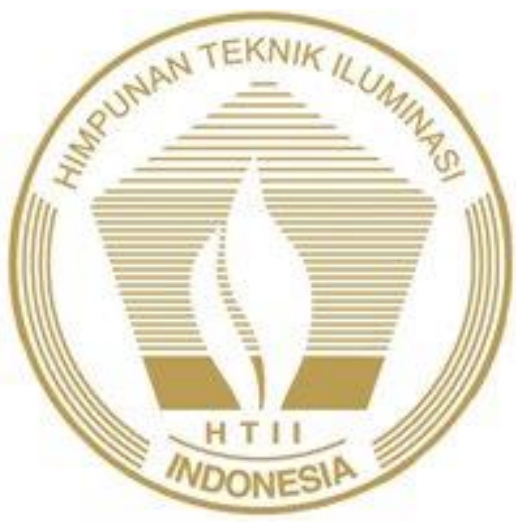

Gambar 1. Logo HTII Lama

Sumber: Instagram HTII

\section{Motoprofesi}

Masyarakat teknik iluminasi terdiri dari anggota masyarakat yang memenuhi kualifikasi dalam bidang iluminasi berdasarkan pendidikan, pengalaman, keahlian yang diakui dalam bidang perlampuan dan yang mempunyai minat besar dalam perlampuan/tata pencahayaan. Motoprofesi, visi, dan misi HTII adalah: jujur, mandiri dan professional.

\section{Visi HTII}

Menjadi wahana efektif yang senantiasa berusaha untuk menciptakan masyarakat professional dibidang iluminasi, guna memenuhi kebutuhan sumber daya manusia yang memiliki kompetensi, kualifikasi dan klasifikasi serta kinerja dunia di bidang Iluminasi di Indonesia.

\section{Misi HTII}

a) Membentuk masyarakat professional dibidang iluminasi yang mampu mendarmabaktikan keahlian dan atau keterampilannya untuk kepentingan bangsa, negara dan kemanusiaan.

b) Menuju terselenggaranya pembangunan dan pengelolaan sarana iluminasi oleh tenaga kerja bangsa Indonesia, dengan memperhatikan mutu, kehandalan dan keamanan yang tinggi, serta kemanfaatan bagi manusia dan lingkungannya.

c) Membina kerjasama dengan lembaga, asosiasi/organisasi, dan industri terkait, langsung ataupun tidak langsung dibidang iluminasi, baik didalam maupun di luar negeri.

Berdasarkan informasi yang didapatkan pada FGD yang dilakukan dengan tim internal HTII dan juga informasi dari website HTII, maka diputuskan untuk mengolah lebih dalam lagi motto yang sudah ada pada HTII yaitu, jujur, mandiri dan professional. Perancangan logo untuk HTII haruslah mewakili motto dari organisasi yang telah dibangun sejak awal. Berdasarkan beberapa upaya ditemukanlah satu kata yang dianggap paling mewakili HTII yaitu "cahaya", maka logo yang dirancang akan menggunakan cahaya sebagai acuan dasar visualnya.

2. Pembuatan konsep creative brief sederhana yang menjadi standar dari sebuah perancangan logo untuk mempermudah pemetaan pikiran. Brief ini digunakan untuk menyusun konsep 
logo dengan proses brainstorming, sketch dan draft desain hingga finalisasi desain, konsep brief kreatif, dapat dilihat pada Tabel 1.

Tabel 1. Konsep Brief Kreatif (Lisfya dan Dawami, 2018)

\begin{tabular}{ll}
\hline Entitas & Organisasi non profit keahlian profesi dalam bidang pencahayaan. \\
& Nama Entitas: HTII (Himpunan Teknik Iluminasi Indonesia) \\
\hline Deskripsi & Himpunan Teknik Iluminasi Indonesia (HTII) merupakan \\
& organisasi yang menghimpun para professional di bidang desain \\
& dan teknik iluminasi (pencahayaan). Organisasi HTII bersifat \\
& nasional. Teknik iluminasi sendiri merupakan pengetahuan tentang \\
& pencahayaan. \\
\hline Masalah & Untuk sebuah organisasi profesi yang telah berdiri cukup lama, sejak \\
& tahun 1991, HTII dirasakan masih kurang dikenal dan kurang \\
& terekspos oleh masyarakat umumnya dan masyarakat konstruksi \\
& pada khususnya. \\
& Logo yang digunakan sekarang dinilai terlalu formal, kurang \\
& mengikuti dinamika yang berkembang yang membutuhkan hal-hal \\
& yang bersifat sederhana dan mudah dipahami. \\
\hline Tujuan & Terpilihnya logo yang merupakan corporate visual identity baru \\
& untuk HTII sebagai wadah bagi semua professional di bidang \\
& pencahayaan atau iluminasi. \\
\hline Target market & $\begin{array}{l}\text { Pembaruan ini ditujukan untuk semua golonga usia, daerah dan } \\
\text { suku. Namun akan lebih difokuskan kepada calon profesional, } \\
\text { profesional muda yang tinggal di daerah perkotaan. }\end{array}$ \\
\hline Tone and manner & Mendesain logo dan corporate visual identity baru yang mewakili \\
\hline Apa yang dilakukan? & citra dari HTII berikut implementasinya ke beberapa media yang \\
diperlukan oleh HTII
\end{tabular}

Berdasarkan brief ini, maka terciptalah 5 alternatif logo desain baru HTII, yang diterjemahkan dari brief yang telah dipaparkan sebelumnya. Konsep desain alternatif 1-3 menggunakan karakter logo basic shape atau pictorial, tujuannya adalah untuk lebih mudah mendapatkan rekognisi. Penggunaan konsep hubungan sebab akibat dan dampak dari sebuah cahaya, apabila suatu cahaya menyorot ke titik atau objek tertentu maka akan muncul bayangan. Hal ini dimaksudkan menjadi citra dari logo baru HTII kapanpun orang membicarakan cahaya maka akan langsung teringat dan muncul HTII. Hal tersebut kemudian dijadikan dasar konsep untuk rancangan 1-3.
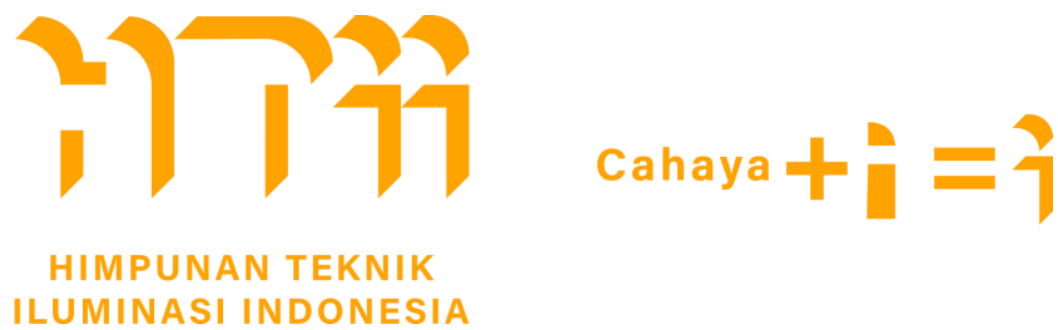

Gambar 2. Alternatif Desain Logo 1

Sumber: Dokumen pribadi, 2020 


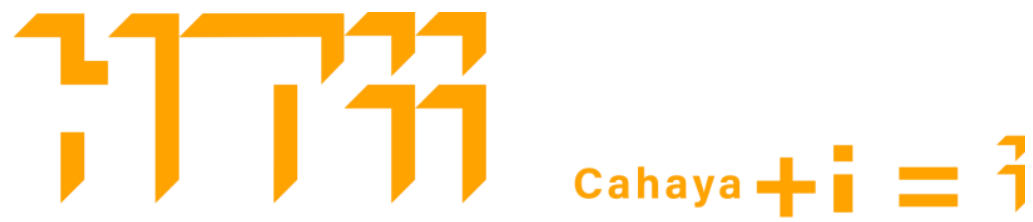

HIMPUNAN TEKNIK

| LUMINAS| |NDONESIA

Gambar 3. Alternatif Desain Logo 2

Sumber: Dokumen pribadi, 2020
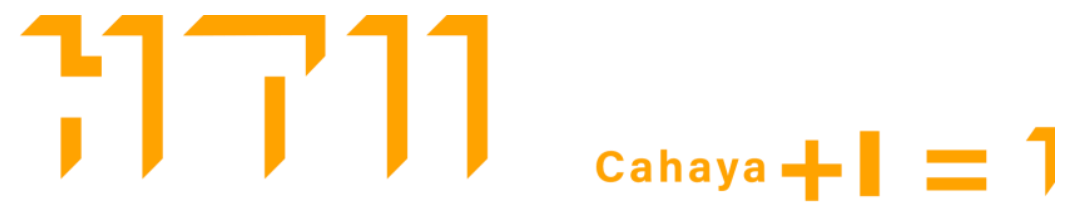

HIMPUNAN TEKNIK

|LUMINAS| |NDONESIA

Gambar 4. Alternatif Desain Logo 3

Sumber: Dokumen pribadi, 2020

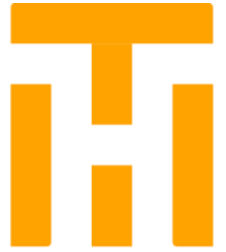

HIMPUNAN TEKNIK

| LUMINAS| INDONESIA

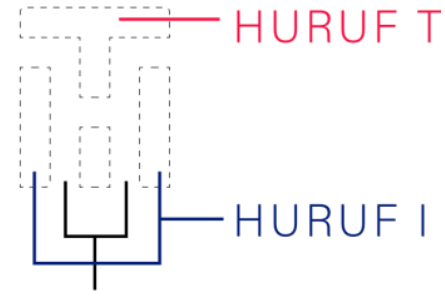

HURUF H

Gambar 5. Alternatif Desain Logo 4

Sumber: pribadi, 2020

Jika pada konsep sebelumnya logo banyak bermain diranah filosopis dan permainan makna visual, konsep keempat ini bermain di ranah literal, memaksimalkan asset yang memang sudah dimiliki HTII juga pada logo sebelumnya yaitu akronim atau lettermark 'HTII'
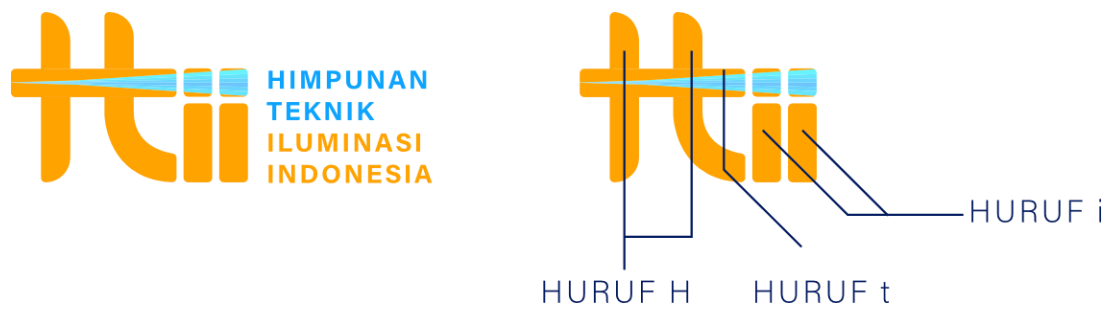

Gambar 6. Alternatif Desain Logo 5

Sumber: pribadi, 2020 
Konsep kelima kurang lebih sama dengan konsep keempat, namun dengan penambahan elemen cahaya sebagai ornament. Kelima konsep ini kemudian diajukan pada Forum internal pengurus HTII terlebih dahulu untuk di seleksi.

1. Sejauh ini diskusi untuk pemilihan logo belum menemukan hasil akhir, pemilihan berjalan dengan penuh pertimbangan mengingat pembaruan logo ini adalah hal krusial bagi HTII karena terkait dengan identitas mereka di publik nantinya.

2. Karena pemilihan logo belum oleh tim internal HTII belum mencapai keputusan final maka perancangan untuk finalisasi logo ditunda hingga minggu keempat Desember 2020.

3. Sembari menunggu hasil keputuhan pemilihan logo yang sudah dilakukan HTII, tim desain mulai menyusun kuisioner untuk pengujian logo. Pengujian ini seperti disebutkan sebelumnya meminjam model dari David E. Carter. Model ini terdiri dari tiga penilaian penting yaitu pembandingan, nilai konsistensi penerapan dan implikasi logo HTII pada media mereka baik online ataupun offline. Pengujian akan dilakukan sebanyak dua tahap yaitu pra (sebelum desain) dan pasca (setelah desain). Pra perancangan akan dilakukan pengumpulan data-data terkait logo HTII sebelum di redesign. Adapun yang akan diukur adalah instrumen memorability, simplicity, element of surprise, timeless, original, versatile, a message, scalable, execution, kemudian pasca akan meminta tanggapan responden terhadap logo setelah dilakukan redesign dengan tolak ukur yang sama dengan pra perancangan. Kuisioner akan dibuat melalui google form. Data kemudian akan dianalisis dan dijadikan sebagai design document reports sebagai penguat dan dasar bagi logo HTII yang telah diperbarui.

4. Setelah hasil terkumpul dan dinilai sudah layak untuk publish, maka selanjutnya akan di lakukan penyerahan master design logo baru HTII yang sudah di finalisasi dalam bentuk corporate visual identity, dan juga pengaplikasian identitas visual yang baru dalam berbagai media, utamanya media sosial yang saat ini masih memiliki sedikit pengikut.

\section{KESIMPULAN DAN SARAN}

Pembaruan logo HTII pada PKM ini menggunakan dominan logo yang berkarakter pictorial, yang dimaksud dalam hal ini adalah draft logo HTII memiliki keunikan tersendiri dari sisi karakter bentuk yang sangat memungkinkan dijadikan sebagai sebuah symbol, lambang, ataupun keperluan image yang lainnya. Karakter berikutnya adalah lettermark. Karakter dari draft desain yang dihasilkan untuk logo baru HTII memiliki tanda yang literal yaitu sebagai tulisan atau huruf yang juga dapat dibaca tentunya selain menjadi lambang dan pictorial. Kedua karakter ini muncul berdasarkan pada hasil diskusi internal dan desk research, serta studi banding yang dilakukan oleh tim desain saat mempelajari beberapa logo organisasi profesi lainnya yang memiliki karakter pictorial dan dominan lettermark. Kedua karakter tersebut dinilai lebih mudah mendapatkan rekognisi dari audiens. Kegiatan ini juga menghasilkan lima konsep yang lahir dari konsep brief kreatif yang dihasilkan dari kolaborasi antara tim HTII dan tim desain yang kemudian membuktikan bahwa untuk melakukan re-desain pada logo sebuah organisasi non profit dibutuhkan pendalaman dan proses yang sangat detail. Metode yang dilakukan pada perancangan ini cukup tepat mulai dari awal perancangan sampai dengan evaluasi perancangannya. Berdasarkan hal ini diharapkan hasil dari rancangan ini pun tidak subjektif dan dapat diterima oleh khalayak umum yang sesuai dengan harapan HTII.

Kegiatan ini pun menyarankan bahwa melakukan pembaruan sebuah logo harus dilakukan dengan berlandaskan data dan konsep. Data diperlukan sebagai landasan awal dan pengukuran untuk mencari alas an penguat untuk dilakukannya re-design sebuah logo. sementara konsep yang 
matang digunakan sebagai rentetan kegiatan pengolahan data secara aplikatif dan implikatif yang melibatkan kemampuan berpikir dan teknis desain. Selain data dan konsep perancangan sebuah logo kemudian perlu disusun dalam timeline waktu yang akurat, mengingat dalam perancangan sebuah logo juga diperlukan waktu untuk memilih dan menimbang logo alternatif mana yang akan di kerjakan sebagai hasil akhir atau final. Kegiatan ini hanya berfokus kepada pembaruan logo sebagai identitas HTII, maka hanya logo saja yang dievaluasi, kedepannya akan sangat baik jika semua kebutuhan media, strategi kreatif, social media engagement juga dilakukan evaluasi agar semua hal yang di-publish HTII menjadi lebih tepat guna dan sasaran.

\section{Ucapan Terima Kasih (Acknowledgement)}

Terimakasih kepada LPPM Universitas Tarumanagara atas biaya untuk kegiatan ini. Juga kepada HTII yang telah bersedia menjadi mitra pelaksanaan PKM.

\section{REFERENSI}

Hardy, G. (2011). Smashing Logo Design The Art of Creating Visual Identities. John Wiley and Sons, United Kingdom.

Listya, A \& Dawami, A.K. (2018). Perancangan Logo Organisasi Forum Komunikasi Masyarakat Peduli Difabel (FKMPD) Klaten. Jurnal Desain, Vol 05. 02, 61-73.

Moleong, L.J. (2018). Metodologi Penelitian Kualitatif. PT Remaja Rosdakarya, Bandung.

Oei, Y.D. dkk. (2013). Pengaruh Perubahan Logo PT. Dua Kelinci Terhadap Persepsi Target Audience Di Surabaya. Jurnal DKV Adiwarna, Universitas Kristen Petra, Vol 01. 02.

Setyanto, Y. Anggarina, P.T., dan Valentina, A. (2017). Branding yang Dilakukan Humas pada

Perguruan Tinggi Swasta. Jurnal Muara Ilmu Sosial, Humaniora, dan Seni. 1(1), 171-182.

Taufano, Ricardo dan Irwansyah. (2020). Brand Personality Ahmad Zaky sebagai Chief

Executive Officer Bukalapak dalam Media Sosial Instagram. Jurnal Komunikasi, 12 (2), 211-230.

https://htii.or.id/ dan https://www.instagram.com/htii_pusat/ 